\title{
Clinical characteristics of patients with arrhythmic mitral valve prolapse in a single tertiary center: prevalence of electrocardiographic and myocardial abnormalities
}

\author{
Agnieszka Zienciuk-Krajka', Ludmiła Daniłowicz-Szymanowicz'1, Karolina Dorniak², Radosław Owczuk³, \\ Damian Kaufmann', Dariusz Zacharek', Alicja Dąbrowska-Kugacka', Monika Figura-Chmielewska', \\ Radosław Nowak', Maciej Kempa', Piotr Kuźmiński', Grzegorz Raczak¹
}

'Department of Cardiology and Electrotherapy, Medical University of Gdansk, Gdańsk, Poland 2Department of Noninvasive Cardiac Diagnostics, Medical University of Gdansk, Gdańsk, Poland ${ }^{3}$ Department of Anaesthesiology and Intensive Therapy, Medical University of Gdansk, Gdańsk, Poland ${ }^{4}$ Cardiology Unit, Hospital of the Ministry of Internal Affairs, Gdańsk, Poland

Correspondence to: Agnieszka Zienciuk-Krajka, $\mathrm{MD}, \mathrm{PhD}$,

Department of Cardiology and Electrotherapy, Medical University of Gdansk,

Dębinki 7, 80-952 Gdańsk phone: +48583493910 e-mail: agzien@gumed.edu.pl Copyright by the Author(s), 2021

Kardiol Pol. 2021; 79 (6): 693-696; DOI: 10.33963/KP.a2021.0008

Received:

February 17, 2021

Accepted:

May 12, 2021

Published online:

May 13, 2021

\section{INTRODUCTION}

Mitral valve prolapse (MVP) related sudden cardiac death (SCD) occurs with an estimated annual risk of $0.2 \%-1.9 \%$ and affects also young and otherwise healthy MVP patients with trivial or absent mitral regurgitation (MR) [1-3]. Several characteristics of the arrhythmogenic MVP (AMVP) were found, including bileaflet MVP, female sex, T-wave inversions (TWI), mitral annular disjunction (MAD), focal fibrosis of papillary muscles (PMs) and adjacent inferobasal LV wall, and frequent/complex ventricular arrhythmias (VA) [1, 3, 4]. The cohorts studied in the MVP series included SCD victims $[2,4,6]$, survivors of cardiac arrest (CA) [3], patients with frequent and complex $V A$ referred for catheter ablation [7, 8], or imaging studies for MR [9]. Little is known, however, about the characteristics of patients diagnosed with AMVP in real-life settings. Given the paucity of data, we aimed to characterize consecutive patients from our institution, in whom features of AMVP were found.

\section{METHODS}

Patients referred to our tertiary center between October 2016 and March 2020 were screened for the presence of AMVP defined as MVP, MAD, curling, and frequent and/or complex VA. Patients underwent a cardiovascular evaluation that included history, physical examination, 12-lead ECG, transthoracic echocardiography, 24-hour Holter monitoring, exercise testing, and LGE-CMR unless contraindicated. Additionally, all patients implanted with an ICD and diagnosed with idiopathic ventricular fibrillation (IVF), i.e., negative for ischemia, cardiomyopathy, and channelopathy, were systematically re-screened, and included in the study group, if signs of AMVP were present. The patients were divided into two groups based on the occurrence of CA in the past medical history and followed prospectively. The institutional review board approved the study and all patients gave informed consent.

\section{Statistical analysis}

All calculations were done using Statistica 13PL (StatSoft, Tulsa, OK, USA). Continuous data were presented either as median (range) or median (IQR); categorical data were given as $\mathrm{n}(\%)$. The normality of continuous data was tested with W Shapiro-Wilk test. U Mann-Whitney test was used for intergroup comparisons. Fisher's exact test was used for categorical data comparisons. $P<0.05$ was adopted as significant.

\section{RESULTS AND DISCUSSION}

Twenty-six patients met the study criteria (Table 1). Twelve (46\%) patients were diagnosed with MVP and/or VA in childhood, at the median age of 9 years. A total of 23 (89\%) patients reported symptoms such as palpitations, dizziness, and fatigue. Among 23 patients implanted with an ICD due to IVF, in 7 (30\%, 2 males) AMVP was subsequently diagnosed. The median age of CA was 28 (range 17-37) years. In all patients, the sentinel VF event occurred while not on 
$\beta$-blockers: at leisure activity $(n=7)$, and night $(n=1)$. In men, CA occurred in the daytime and was not associated with stress/exercise. In 3 women CA occurred in relation to pregnancy or postpartum period, i.e., in the $8^{\text {th }}$ week of pregnancy, two and six months post-delivery. Noteworthy, all but one $C A$ patient were consulted by a cardiologist for a median period of 7 (range $0-16$ ) years before CA. Upon observation, in 3 patients (two males) appropriate ICD therapies occurred, with recurring electrical storms in one.

In the non-CA group the most common referral diagnoses were: frequent /complex VA ( $n=14 / 18,78 \%)$, either alone $(n=7)$ or with MVP $(n=5)$ and/or a suspicion of NC cardiomyopathy $(n=2)$, a suspicion of the long QT syndrome $(n=1)$; a cardiac murmur and palpitations $(n=1)$, syncope $(n=1)$, or arterial hypertension $(n=1)$.

All patients had bileaflet MVP with curling, MAD and preserved LVEF. In 13 (50\%) mild/minimal MR, in 12 (46.2\%) moderate, and one patient (3.8\%) severe MR was found. CMR was performed in 12 (46\%), and in 8/12 (67\%) patients criteria for LVNC were fulfilled, with a median NC/C ratio of 3.2 (range 1.4-5.5). The NC pattern was associated with thinning of the compact myocardial layer to $2-4 \mathrm{~mm}$ in the anterior and/or lateral wall, and an abnormal structure/fragmented (trabeculated) base of PMs. In 9/12 (75\%) subtle dispersed LGE was identified in the basal inferolateral wall and/or mid-inferolateral segments or PMs.

In all patients complex VA was recorded with $>1$ (median 3) PVCs morphology predominantly of the RBBB pattern from the posterior PM. In 15/26 (58\%) patients three-beat nonsustained VT (nsVT), and in 14/26 patients nsVT lasting $>3$ beats occurred. In Holter recordings, PVCs occurred predominantly at night in two, and during the daily activity in the remaining patients. Of the 19 individuals who underwent exercise stress treadmill testing, an increase in frequency and VA complexity was observed in 3, resolution of VA in 6, VA onset in recovery stage in 3 , and persistent VA with no/minimal change in 4 patients.

TWI was observed in the inferior leads in 20 (77\%) patients, in 15 (58\%) both normal ECGs and TWI were found. Among a total of 165 ECGs (6 strips/patient), 87 (53\%) ECGs were normal, the remaining showed TWI in different configurations in $\geq 2$ inferior leads. Only one CA survivor presented with normal ECG in all strips when compared to $5 / 18$ nonCA patients ( $12.5 \%$ vs $28 \%$; $P=0.378$ ).

Twenty-four (92\%) patients were treated with betablockers (bisoprolol, metoprolol, nadolol), which did not prevent malignant VA in ICD patients. Class Ic antiarrhythmics (propafenone or flecainide) alone or with betablocker were used in 2 patients with modest efficacy. One patient underwent mitral valve repair for significant MR 3 years after CA, with no VTA during follow-up.

The $C A$ and non-CA patients differed for heart rate $68(64-71)$ vs $76(64-85)$ bpm; $P=0.04$, E/e'ratio - 7.7 (6.5$9.2)$ vs $5.9(5.4-6.7) ; P=0.04$, and the fastest rate of nsVT $-220(181-279)$ vs $178.5(150-200)$ bpm; $P=0.04$ (Table 1$)$.
The presence of LV non-compaction in AMVP patients seems to contrast with the results of the studies reporting MVP as the only cardiac abnormality in SCD or out-of-hospital CA series [2-4]. In these studies, however, patients with any cardiomyopathy were a priori excluded. Recently, Garbi et al. showed that $81 \%$ of SCD cases with „lone" MVP had microscopic LV fibrosis associated with hypertrophy and degeneration of the myocytes, and $11 \%$ also had RV fibrosis [10]. The diffuse LV fibrosis was also demonstrated in AMVP by reduced post-contrast T1 times on CMR imaging [11]. Lastly, in MVP patients, VA arise from fascicles, LV outflow tract or septal aspect of the mitral annulus, RV outflow tract and free wall $[3,7]$ indicating the presence of more extensive arrhythmogenic substrate. In this context higher E/e'ratio, which is a noninvasive insight into diastolic LV pressures, might reflect more extensive disease (fibrosis) in CA patients. Various mechanisms for VA in the setting of MVP were postulated, with focal fibrosis (positive LGE) and consequent regions of conduction block promoting re-entry arrhythmia, and interstitial fibrosis (abnormal T1) resulting in spontaneous diastolic depolarization and abnormal automaticity [11]. To the best of our knowledge, E/e' ratio was not previously discussed in AMVP patients in the context of SCD risk.

Interestingly, inferior TWI was present in $77 \%$ of patients, with intermittent TWI in 58\% of AMVP cases. This finding is of importance since TWI is considered a part of the diagnostic tetrad in AMVP $[3,4,9]$. The observed variability, however, may be also related to cardiac memory.

Our study showed that almost all patients were consulted by a cardiologist before CA, moreover, half of them was supervised since childhood/adolescence. Thus, patients with malignant MVP are under the specialist care for a long time, while their SCD risk goes unrecognized. In this context, the observed differences between $C A$ and nonCA patients with regard to the rate of nsVT and E/e'ratio seem to be interesting, however, they need to be validated in larger groups of AMVP patients, preferably the multi-center registry, to establish risk stratification algorithms for SCD in MVP.

Finally, in women CA tends to occur in pregnancy or after delivery, pointing to a possible relation of hormonal status to VA. Similarly, Syed et al. found that in 2 of 6 females, pregnancy and a menstrual cycle were triggers for appropriate ICD shocks [7].

\section{CONCLUSIONS}

AMVP is a clinical syndrome characterized by intermittent TWI and myocardial abnormalities, such as LV non-compaction. AMVP patients after CA differ by faster rates of nonsustained VT and higher E/e' ratio from non-CA patients. We support the view that patients with IVF should be systematically reassessed for the presence of new arrhythmogenic conditions, including AMVP, which may constitute $30 \%$ of IVF cases. 
Table 1. Characteristics of the study patients and group comparisons

\begin{tabular}{|c|c|c|c|c|}
\hline Variables & $\begin{array}{l}\text { Overall AMVP group } \\
\qquad(n=26)\end{array}$ & $\begin{array}{l}\text { Non-CA group } \\
\quad(n=18)\end{array}$ & $\begin{array}{l}\text { CA groupa } \\
\qquad(n=8)\end{array}$ & $P$-value \\
\hline Age, years, median (IQR) & $36(33.5-46)$ & $36.5(35-48)$ & $36.5(29.5-44)$ & 0.44 \\
\hline Women, n (\%) & $18(69)$ & $12(67)$ & $6(75)$ & 0.523 \\
\hline Follow-up, months, median(IQR) & $27.5(21-103)$ & $24.5(18-64)$ & $108(40-177)$ & 0.009 \\
\hline Weight, kg, median (IQR) & $65(60-71)$ & $64(56-71)$ & $65(63-75)$ & 0.36 \\
\hline Height, cm, median (IQR) & $173(170-179)$ & $174(170-180)$ & $168.5(166-178)$ & 0.08 \\
\hline $\begin{array}{l}\text { Body mass index, } \mathrm{kg} / \mathrm{m}^{2} \text {, median } \\
\text { (IQR) }\end{array}$ & $21(20-23)$ & $20.5(20-23)$ & $22.4(22-25.5)$ & 0.08 \\
\hline $\begin{array}{l}\text { Age of first symptoms, years, } \\
\text { median (IQR) }\end{array}$ & $18(9-28)$ & $18(8-26)$ & $17.5(9.5-29.5)$ & 0.98 \\
\hline Symptomatic PVCs, n (\%) & $23(89)$ & $16(89)$ & $7(88)$ & 0.686 \\
\hline Syncope, n (\%) & $4(15)$ & $3(17)$ & $1(13)$ & 0.64 \\
\hline$\beta$-blockers, n (\%) & $24(92)$ & $16(89)$ & $8(100)$ & 0.471 \\
\hline Pacemaker, n (\%) & $1(4)$ & 0 & $1(12.5)$ & 0.31 \\
\hline ICD, $\mathrm{n}(\%)$ & $9(35)$ & $2(11)$ & $7(88)$ & 0.0004 \\
\hline \multicolumn{5}{|l|}{ ECG data } \\
\hline No of PVCs, median (IQR) & $3250(1803-8675)$ & 3000 (1800-9200) & $3250(1737-4500)$ & 0.98 \\
\hline $\begin{array}{l}\text { The shortest coupling interval, } \\
\text { ms, median (IQR) }\end{array}$ & $400(360-440)$ & $420(370-440)$ & $360(330-440)$ & 0.11 \\
\hline $\begin{array}{l}\text { The longest coupling interval, } \\
\text { ms, median (IQR) }\end{array}$ & $480(480-543)$ & $520(480-550)$ & $480(460-516)$ & 0.11 \\
\hline $\begin{array}{l}\text { Max VT rate, bpm, median } \\
\text { (IQR) }\end{array}$ & $188(170-207)$ & $178.5(150-200)$ & $220(181-279)$ & 0.04 \\
\hline HR, bpm, median (IQR) & $75(65-85)$ & $75.5(64-85)$ & $67.5(64-71)$ & 0.04 \\
\hline PR, ms, median (IQR) & $150(130-160)$ & $150(130-160)$ & $170(150-195)$ & 0.13 \\
\hline QRS, ms, median(IQR) & $90(90-110)$ & $100(90-100)$ & $95(85-100)$ & 0.86 \\
\hline QT, ms, median (IQR) & $400(380-420)$ & $400(360-430)$ & $420(380-440)$ & 0.43 \\
\hline QTc, ms, median (IQR) & $437(420-455)$ & $440(420-456)$ & 439 (427-452) & 0.98 \\
\hline Inferior TWI, n (\%) & $20(77)$ & $13(72)$ & $7(88)$ & 0.38 \\
\hline Intermittent TWI, n (\%) & $14(54)$ & $9(50)$ & $5(63)$ & 0.44 \\
\hline \multicolumn{5}{|l|}{ Echocardiographic data } \\
\hline $\begin{array}{l}\text { Curling distance, mm, median } \\
\text { (IQR) }\end{array}$ & $6(5-7)$ & $6(4-7)$ & $7(5-8)$ & 0.35 \\
\hline MAD, mm, median (IQR) & $11(9-12)$ & $10(9-12)$ & $11(8-13)$ & 0.97 \\
\hline LVEF, \%, median(IQR) & $60(55-60)$ & $60(55-60)$ & $58(53-63)$ & 0.93 \\
\hline GLS, \%, median (IQR) & $-21(-22.5-[-20])$ & $-21.5(-24.5-[-20])$ & $-20.5(-22-[-19])$ & 0.26 \\
\hline LVESD, mm, median(IQR) & $32(28-35)$ & $32(30-35)$ & $29.5(26-37)$ & 0.68 \\
\hline LVEDD, mm, median (IQR) & $51(47-55)$ & $51(49-55)$ & $50(46-55)$ & 0.74 \\
\hline $\begin{array}{l}\text { LA diameter, mm, median } \\
\text { (IQR) }\end{array}$ & $37(34-42)$ & $37(35-43)$ & $36(32-42)$ & 0.52 \\
\hline $\mathrm{LAVI}, \mathrm{ml} / \mathrm{m}^{2}$, median (IQR) & $31(23-40)$ & $27(23-41)$ & $36(22-45)$ & 0.9 \\
\hline $\mathrm{e}^{\prime}$, median (IQR) & $0.11(0.1-0.12)$ & $0.11(0.1-0.12)$ & $0.11(0.09-0.14)$ & 0.97 \\
\hline E/e', median (IQR) & $6.2(5.6-6.8)$ & $5.9(5.4-6.7)$ & $7.7(6.5-9.2)$ & 0.04 \\
\hline
\end{tabular}

aThe patient with symptomatic polymorphic VT/VF and DDD pacemaker was also included in this group.

Abbreviations: GLS, global longitudinal strain; HR, heart rate; ICD, implantable cardioverter-defibrillator; LAVI, left atrial volume index; LVEDD, left ventricular end-diastolic diameter LVEF, left ventricular ejection fraction; LVESD, left ventricular end-systolic diameter; MAD, mitral annular disjunction; MVP, mitral valve prolapse; PVCs, premature ventricular contractions; TWI, T-Wave inversion; VT, ventricular tachycardia

\section{Article information}

Conflict of interest: None declared.

Open access: This article is available in open access under Creative Common Attribution-Non-Commercial-No Derivatives 4.0 International (CC BY-NC-ND 4.0) license, allowing to download articles and share them with others as long as they credit the authors and the publisher, but without permission to change them in any way or use them commercially. For commercial use, please contact the journal office at kardiologiapolska@ptkardio.pl.

How to cite: Zienciuk-Krajka A, Daniłowicz-Szymanowicz L, Dorniak $\mathrm{K}$, et al. Clinical characteristics of patients with arrhythmic mitral valve prolapse in a single tertiary center: prevalence of electrocardiographic and myocardial abnormalities. Kardiol Pol. 2021; 79(6): 693-696, doi: 10.33963/KP.a2021.0008.

\section{REFERENCES}

1. Miller MA, Dukkipati $S R$, Turagam $M$, et al. Arrhythmic mitral valve prolapse: JACC review topic of the week. J Am Coll Cardiol. 2018; 72(23 Pt A): 2904-2914, doi: 10.1016/j.jacc.2018.09.048, indexed in Pubmed: 30522653.

2. Anders S, Said S, SchulzF, et al. Mitral valve prolapse syndrome as cause of sudden death in young adults. Forensic Sci Int. 2007; 171(2-3): 127-130, doi: 10.1016/j.forsciint.2006.10.011, indexed in Pubmed: 17140755.

3. Sriram CS, Syed FF, Ferguson ME, et al. Malignant bileaflet mitral valve prolapse syndrome in patients with otherwise idiopathic out-of-hospital cardiac arrest. J Am Coll Cardiol. 2013; 62(3): 222-230, doi: 10.1016/j. jacc.2013.02.060, indexed in Pubmed: 23563135.

4. Basso C, Perazzolo Marra M, Rizzo S, et al. Arrhythmic mitral valve prolapse and sudden cardiac death. Circulation. 2015; 132(7): 556-566, doi: 10.1161/CIRCULATIONAHA.115.016291, indexed in Pubmed: 26160859. 
5. Dejgaard LA, Skjølsvik ET, Lie ØH, et al. The mitral annulus disjunction arrhythmic syndrome. J Am Coll Cardiol. 2018; 72(14): 1600-1609, doi: 10.1016/j.jacc.2018.07.070, indexed in Pubmed: 30261961.

6. Han HC, Parsons SA, Teh AW, et al. Characteristic histopathological findings and cardiac arrest rhythm in isolated mitral valve prolapse and sudden cardiac death. J Am Heart Assoc. 2020; 9(7): e015587, doi: 10.1161/JAHA.119.015587, indexed in Pubmed: 32233752.

7. Syed FF, Ackerman MJ, McLeod CJ, et al. Sites of successful ventricular fibrillation ablation in bileaflet mitral valve prolapse syndrome. Circ Arrhythm Electrophysiol. 2016; 9(5): e004005, doi: 10.1161/CIRCEP.116.004005, indexed in Pubmed: 27103091.

8. Bumgarner JM, Patel D, Kumar A, et al. Management and outcomes in mitral valve prolapse with ventricular arrhythmias undergoing ablation and/or implantation of ICDs. Pacing Clin Electrophysiol. 2019; 42(4): 447-452, doi: 10.1111/pace.13613, indexed in Pubmed: 30680747.

9. Nordhues $B D$, Siontis $K C$, Scott $C G$, et al. Bileaflet mitral valve prolapse and risk of ventricular dysrhythmias and death. J Cardiovasc Electrophysiol. 2016; 27(4): 463-468, doi: 10.1111/jce.12914, indexed in Pubmed: 26749260.

10. Garbi M, Lancellotti P, Sheppard MN. Mitral valve and left ventricular features in malignant mitral valve prolapse. Open Heart. 2018; 5(2): e000925, doi: 10.1136/openhrt-2018-000925, indexed in Pubmed: 30364469.

11. Bui AH, Roujol S, Foppa M, et al. Diffuse myocardial fibrosis in patients with mitral valve prolapse and ventricular arrhythmia. Heart. 2017; 103(3): 204-209, doi: 10.1136/heartjnl-2016-309303, indexed in Pubmed: 27515954. 